\title{
"Adam Smith and Social Justice: the Ethical Basis of the Wealth of Nations"
}

\author{
JACOB OSSAR \\ The University of Kansas
}

\section{Introduction}

Many in the West seem to regard the collapse of the so-called communist regimes in the Eastern Europe and the Soviet Union as proof that capitalism is the only viable economic system. These writers often consider it one of capitalism's strengths that it is "value neutral" or "nonideological." They see economics as a purely logistic science that deals with finding the most efficient way to reach given ends. ${ }^{1}$ On this view, capitalism succeeds where communism fails because it builds on objective facts and works with human beings as they are, rather than hobbling itself with ethical constraints and trying to work with human beings as they ought to be.

Accepting this "engineering" approach to economics only apparently makes questions about the good life disappear. In order to justify any political or economic theory, one must show that it meets essential human needs and otherwise promotes the good life for those who employ it. ${ }^{2}$ This, in turn, requires that one decide what human beings are, what motivates them, and what is valuable in a human life. I call this set of claims about human nature a thinker's "philosophical anthropology." Although "value neutral" economics seem at first glance to allow each individual to make up his or her own mind about how to live and simply explains the best way to employ resources reach those goals, in fact such economic theories merely leave their ethical foundations unstated.

1 Amartya Sen calls this the "engineering" approach to economics in "Economic Behavior and Moral Sentiments," in On Ethics and Economics, (Oxford: Blackwell, 1987). (Hereafter referred to as Sen). I am grateful to Ann Cudd for her help and comments on this project.

2 I am here implicitly relying upon the idea that no political or economic theory can entirely ignore normative questions and be purely descriptive. Although I agree that giving an accurate description of economic activity is the primary goal of any economic theory, we would have no compelling reasons to accept policy recommendations based on such a theory unless it could provide convincing arguments that we would be better off if we follow its recommendations rather than pursue some alternative course of action. In order to justify claims that one outcome is better than another, a theory must rely on at least some minimal normative standards. 
In this paper, I will examine the works of Adam Smith, one of the most influential exponents of modern capitalist economic theory. ${ }^{3}$ I will argue that his theory does rest and must rest on a number of claims that have far-reaching ethical and political implications. Some of the most interesting and important of these concern the role of the poor in a capitalist economy. As Smith says, "no society can surely be flourishing and happy, of which the far greater part of the members are poor and miserable." By examining Smith's discussion of the poor, I hope to reveal both the philosophical anthropology implicit in capitalist theory and its use in the theory's ethical justification.

\section{Smith's Philosophical Anthropology}

Smith does not spend much time in the Wealth of Nations articulating his philosophical anthropology, so I will rely primarily on his The Theory of Moral Sentiments for my exposition of it. Since Smith published a sixth edition of this work shortly before his death in 1790, it seems safe to assume that he did not see a conflict between his moral theory and the economic theory that he presents in the Wealth of Nations.5 Those wanting to take an Althusserian approach and focus exclusively on Smith's economics would have to explain why Smith continued to update and develop his moral theory until the end of his life.

For Smith, human beings have a strong instinct for survival. 6 This instinct, coupled with our "propensity to truck, barter, and exchange one thing for another"7 causes us to form societies in order to produce the goods we need to survive. Society is held together by, and economic activity is driven by, the principles of sympathy (or fellow-feeling) and selflove, and the secondary principles that are derived from them.

Sympathy is "our fellow-feeling with any passion whatever." Through sympathy, we imagine ourselves in the place of others and experience their feelings. Sympathy is a pleasurable sensation that draws human

${ }^{3}$ Smith himself was well aware of the relationship between economics and ethics, but many of his modern followers seem to have lost sight of this fact. See Sen, pg. 2.

4 Adam Smith, An Inquiry into the Nature and Causes of the Wealth of Nations, R.H. Campbell, A.S. Skinner, and W.B. Todd eds., (Indianapolis: Liberty Classics, 81), l.viii.36 (pg. 96). (Hereafter referred to as WN).

5 Adam Smith, The Theory of the Moral Sentiments, D.D. Raphael and A. L. Macfie eds., (Indianapolis: Liberty Classics, 1982), pg. 20. (Hereafter referred to as TMS. All quotations are from the sixth edition of 1790).

6 See TMS VII.ji.I.34 (pg. 287). "Nature, in her sound and healthful state, seems never to prompt us to suicide."

7 WN I.ii.1-2 (pp. 25-26).

8 TMS I.i.I.4 (pg. 10). 
beings together and, because we desire that others sympathize with us, serves as the foundation of ethics.9 Not only do we desire the sympathy of others, we desire to be worthy of their sympathy. "We desire both to be respectable and to be respected. We dread both to be contemptible and to be contemned."10 However, since the possession of riches often gains us more respect than the possession of virtue, the desire for approbation leads us to pursue wealth. ${ }^{11}$ Smith argues that we desire wealth not for its own sake, but because of vanity; in the Theory of Moral Sentiments he notes "the rich man glories in his riches, because he feels that they naturally draw upon him the attention of the world ...."12 Smith makes a similar point in the Wealth of Nations: "with the greater part of rich people, the chief enjoyment of riches consists in the parade of riches, which in their eyes is never so compleat as when they appear to possess those decisive marks of opulence which nobody can possess but themselves." 13

This feature of human nature creates an important problem for Smith:

This disposition to admire, and almost to worship, the rich and the powerful, and to despise, or, at least, to neglect, persons of poor and mean condition, though necessary both to establish and maintain the distinction of ranks and the order of society, is, at the same time, the universal cause of the corruption of our moral sentiments." 14

Note that Smith is not troubled by hierarchy per se; he seems to regard the existence of social classes as part of a well-ordered society. Furthermore, without hierarchy and the corresponding desire to be admired for their relative wealth, people would lack one of the major incentives that Smith thinks will drive them to work hard to acquire riches. Even so, this desire must be kept within bounds because it causes us to despise the poor illegitimately, and can lead us to commit crimes in the pursuit of wealth. The problem is aggravated by our propensity to weigh our own happiness more heavily than the happiness of others. ${ }^{15}$ Our desire to be not only respected but respectable, combined with our knowledge that aggressive impulses must be contained, leads us to create

${ }^{9}$ Although sympathizing with someone who is unhappy causes us to share in his or her unhappiness, the act of sympathizing itself is still pleasant.

${ }^{10}$ TMS I.iii.2 (pg. 62).

11 TMS l.iii.3.3 (pg. 62).

12 TMS l.iii.2.1 (pp 50-51).

${ }^{13}$ WN I.xi.c.31 (pg. 190).

14 TMS l.iii.3.1 (pg. 61).

${ }^{15}$ TMS II.ji.2.1 (pp. 82-3). 
knowledge that aggressive impulses must be contained, leads us to create ethical rules. To check our ambition, vanity, and self-love, we learn to consider our actions from the point of view of an impartial spectator, which leads us to weigh everyone's happiness equally when acting and when formulating moral principles. We must do this, because if we fail to check our self-love, others will resent us and we will become "the object of their hatred and indignation."16

The principle of sympathy and its consequence, the desire to be admirable and to be admired, when combined with the principle of selflove provide the motive force for humans in Smith's economic theory. To gain the approbation of others, we produce far more goods than we can use. This creates a surplus that we trade with others, which fosters the division of labor and which, through a "trickle down" effect, is supposed to provide for the sustenance of the poor.

\section{Implications of Smith's Philosophical Anthropology}

Smith's account of how and why economic transactions occur has a number of significant theoretical consequences for the poor. I have already noted that the existence of social classes is an important part of Smith's economic theory. In order to justify this aspect of his theory, Smith must do more than merely show that the presence of social classes increases productivity; he must also show that this productivity will benefit the poor, and that the economic system on the whole is fair. Smith attempts to do this by asserting that the effects of poverty are not nearly so dire as commonly supposed, and by drawing a sharp distinction between duties of justice and duties of beneficence.

Smith, no doubt drawing on Stoic philosophy, denigrates the importance of material goods. He claims that we do not desire riches for their own sake, but because having them draws the attention and admiration of others. Power and riches in and of themselves are

... enormous and operose machines contrived to produce a few trifling conveniencies to the body, consisting of springs the most nice and delicate, which must be kept in order with the most anxious attention, and which in spite of all our care are ready every moment to burst into pieces, and to crush in their ruins their unfortunate possessor. They are immense fabrics, which it requires the labour of a life to raise, which threaten every moment to overwhelm the person that dwells in them, and which while they stand, though they may save him from some smaller inconveniencies, can

${ }^{16}$ TMS II.ii.2.1 (pg. 83). 
protect him from none of the severer inclemencies of the season. They keep off the summer shower, not the winter storm, but leave him always as much, and sometimes more exposed than before, to anxiety, to fear, and to sorrow; to diseases, to danger, and to death. ${ }^{17}$

This description occurs in a long passage in which Smith describes the adverse effects suffered by "the poor man's son, whom heaven in its anger has visited with ambition" in his pursuit of wealth and power. ${ }^{18}$ This unfortunate

submits in the first year, nay in the first month of his application, to more fatigue of body and more uneasiness of mind than he could have suffered through the whole of his life from the want of them [the conveniences afforded by wealth]. ${ }^{19}$

Smith's conclusion, then, is that wealth is not an important component of a happy life, and that the pursuit of wealth can actually detract from one's felicity.

The desire to acquire wealth is useful, however, because the rich

consume little more than the poor, and in spite of their natural selfishness and rapacity, though they mean only their own conveniency, though the sole end which they propose from the labours of all the thousands whom they employ, be the gratification of their own vain and insatiable desires, they divide with the poor the produce of all their improvements. They are lead by an invisible hand to make nearly the same distribution of the necessaries of life, which would have been made, had the earth been divided into equal portions among all its inhabitants. ${ }^{20}$

${ }^{17}$ TMS IV.I.8 (pp. 182-83).

${ }^{18}$ TMS IV.I.8 (pg. 181).

19 TMS IV.I.8 (pg. 181). Smith's findings, though probably distressingly accurate descriptions of the fate of ambitious paupers, are suspect. The poor man's son who must struggle every minute to acquire wealth may indeed undergo the strain and ultimate misery Smith describes. However, the rich man's son, born into great wealth, may enjoy that wealth without having to go through the trouble of earning it, and can hire others to endure the drudgery of managing the family fortune.

20 TMS IV.1.10 (pp 184-85). 
Smith's famous idea of the "invisible hand" allows him to argue that his economic theory will provide adequately for the poor and explain the mechanism by which this process occurs.

Smith does not believe that the inequality of wealth between rich and poor is a serious problem, both because such inequalities are necessary to the dynamics of the economy and because the poor are not suffering unduly in any case. Assertions that living in poverty is not a great misfortune appear constantly in the Theory of Moral Sentiments. For example, Smith states that

[i]n ease of body and peace of mind, all the different ranks of life are nearly upon a level, and the beggar, who suns himself by the side of the highway, possesses that security which kings are fighting for. ${ }^{21}$

Even more outrageously, he asserts that if you "take the whole earth at an average, for one man who suffers pain or misery, you will find twenty in prosperity and joy, or at least in tolerable circumstances."22 Smith gives no source or empirical evidence for this dubious and optimistic pronouncement. In the Wealth of Nations, Smith presents a lengthy demonstration that the wages of the poor in Britain are well above the "lowest rate which is consistent with common humanity." 23 His famous statement that "no society can surely be flourishing and happy, of which the far greater part of the members are poor and miserable" should be read in light of his understanding of what constitutes poverty and misery. 24

Smith not only attempts to prove that most paupers live tolerable lives, but also that it is not the responsibility of the rich to care for those that do not. He asserts, contra "whining and melancholy moralists," 25 that it is undesirable even to try caring too much about the one man out of twenty whom poverty makes miserable. He maintains that

whatever interest we take in the fortune of those with whom we have no acquaintance or connexion, and who are placed altogether out of the sphere of our activity, can produce only anxiety to ourselves, without any manner of advantage to them. ${ }^{26}$

21 TMS IV.I.11 (pg. 185).

22 TMS III.3.9 (pg. 140). It is interesting to compare this claim with John Stuart Mill's calculation that nineteen-twentieths of mankind involuntarily do without happiness.

${ }^{23}$ WN I.viii.28-WN I.viii.35 (pp. 91-96).

24 WN I.viii.36 (pg. 96).

25 TMS III.3.9 (pg. 139).

${ }^{26}$ TMS III.3.9 (pg. 140). 
can produce only anxiety to ourselves, without any manner of advantage to them. ${ }^{26}$

Concern for paupers is unnecessary because, although human beings live in societies and are dependent on each other for survival to some extent,

[elvery man is, no doubt, by nature, first and principally recommended to his own care; and as he is fitter to take care of himself, than of any other person, it is fit and right that it should be so. ${ }^{27}$

A person's main moral duty is to friends, family, and him-or herself. Poor people, with the aid of God, should take care of themselves and each other. 28

Smith's conception of human beings as atomistic, autonomous individuals allows him to establish a sharp distinction between duties of justice and duties of beneficence. Justice is the "negative virtue," displayed by a man who "barely abstains from violating either the person, or the estate, or the reputation of his neighbours."29 A violation of justice "does real and positive hurt to some particular persons."30 By way of contrast, beneficence is the positive virtue of one who from love, gratitude, or friendship actively seeks to aid others. While failures of justice cause real harm, failures of beneficence merely "disappoint of the good which might reasonably have been expected," and as such are the proper object of "dislike and disapprobation," but not of punishment. ${ }^{31}$ Duties of justice are obligatory and lapses of duty may be punished by force; duties of beneficence are meritorious but optional, and failure to perform them is hateful but not strictly wrong. This is because "Islociety may subsist. though not in the most comfortable state, without beneficence; but the prevalence of injustice must utterly destroy it. ${ }^{\text {"32 }}$

Smith's ethical theory is a perfect example of what Carol Gilligar terms an "ethic of rights." He sees people primarily as independent autonomous beings in competition with each other for material goods social standing, etc. An individual can subsist with only minima: cooperation from others, provided only that they act justly and do noi

${ }^{26}$ TMS III.3.9 (pg. 140).

27 TMS Il.ii.2.1 (pg. 82). Note here that Smith assumes that what is natura is what is good. Like his friend David Hume, he is generally very carefu not to reason from is to ought.

28 TMS VI.ji.3.6 (pg. 237).

29 TMS 11.1 .1 .9 (pg. 82).

30 TMS Il.ii.1.5 (pg. 79).

31 TMS Il.i.1.3 (pg. 78).

${ }^{32}$ TMS II.ii.3.3 (pg. 86). 
interfere with him or her. Helping others is admirable, but not strictly necessary: the rich do the poor no injustice as long as they refrain killing or robbing them. Thus, capitalism is justified not only because of its productivity, but on ethical grounds as well.

\section{Critique}

As we have seen, Smith must show that the poor will not have to endure excessive suffering under his system. He therefore paints a romanticized picture of the poor as humble but happy people who often surpass their "betters" in virtue and who, spared the burden of riches, enjoy an enviable amount of leisure and peace of mind. However, there are a number of reasons to be skeptical of Smith's sanguine estimation of the condition of the poor (especially the poor of his time), and many passages in Smith's own writings seem to undermine this position. Compare the following two passages, the first concerning "savages" and the second concerning the poor in civilized countries:

[Savages] are so miserably poor, that, from mere want, they are frequently reduced, or, at least, think themselves reduced, to the necessity sometimes of directly destroying, and sometimes of abandoning their infants, their old people, and those afflicted with lingering diseases, to perish with hunger, or to be devoured by wild beasts. 33

... in civilized society it is only among the inferior ranks of people that the scantiness of subsistence can set limits to the further multiplication of the human species; and it can do so in no other way than by destroying a great part of the children which their fruitful marriages produce. ${ }^{34}$

Although in civilized countries the poor are not in much danger of being devoured by wild beasts and do not openly abandon infants, Smith recognizes that hunger still haunts them. It may well be that fewer people in civilized societies suffer from hunger than in "savage" ones, but the prevalence of hunger among the poor in civilized society does raise questions about whether they are really as well off as Smith often makes them out to be. labor:

Consider, too, the conditions under which the leisured and happy poor

33 WN [I].4 (pg. 10).

34 WN I.viii.40 (pg. 98). 
The man whose whole life is spent in performing a few simple operations, of which the effects too are, perhaps, always the same, or very nearly the same, has no occasion to exert his understanding, or to exercise his invention in finding out expedients for removing difficulties which never occur. He naturally loses, therefore, the habit of such exertion, and generally becomes as stupid and ignorant as it is possible for a human creature to become. The torpor of his mind renders him, not only incapable of relishing or bearing a part in any rational conversation, but of conceiving any generous, noble, or tender sentiment, and consequently of forming any just judgment concerning many even of the ordinary duties of private life. ${ }^{35}$

Since, for Smith, sentiment is the foundation of morality, it would appear from this passage that most of those living in poverty are incapable of exercising any significant degree of moral virtue. It also seems unreasonable to expect that someone who is incapable of "forming any just judgement concerning many even of the ordinary duties of private life" will be able to live long or well.

Some of the apparent contradictions can be reconciled if we distinguish between the rural poor and urban laborers. For instance, note that Smith's above account applies only to those engaged in simple, repetitive occupations, i.e. primarily urban workers employed in some type of factory or workshop. Smith explicitly separates these urban laborers from their country counterparts:

Not only the art of the farmer, the general direction of the operations of husbandry, but many inferior branches of country labour require much more skill and experience than the greater part of mechanick trades.... His [the country laborer's] understanding. . . being accustomed to consider a greater variety of objects, is generally much superior to that of the other, whose whole attention from morning till night is commonly occupied in performing one or two very simple operations. ${ }^{36}$

The nuanced understanding of the poor that Smith demonstrates in this passage is largely absent in many other parts of Smith's writings. He tends to write and think of the poor as an undifferentiated, monolithic group, and

35 WN V.i.f.50 (pg. 782).

${ }^{36}$ WN I.X.c.24 (pp. 143-44). 
often seems to be thinking exclusively of country laborers when writing of the poor, as in the following passage:

In the middling and inferior stations of life, the road to virtue and that to fortune, to such fortune, at least, as men in such stations can reasonably expect to acquire, are, happily in most cases, very nearly the same. In all the middling and inferior professions, real and solid professional abilities, joined to prudent, just, firm, and temperate conduct, can very seldom fail of success. . . . Either habitual imprudence, however, or injustice, or weakness, or profligacy, will always cloud, and sometimes depress altogether, the most splendid professional abilities.... The success of such people, too, almost always depends upon the favour and good opinion of their neighbors and equals. ... In such situations, therefore, we may generally expect a considerable degree of virtue; and, fortunately for the good morals of society, these are the situations of by far the greater part of humankind. ${ }^{37}$

The success of small farmers and village artisans may depend on neighbors and equals, but the this does not hold as strongly, if at all, for factory workers. In largely anonymous urban environments, employers are unlikely to know or care much about the moral character of their unskilled workers. Furthermore, it would be odd to expect "a considerable degree of virtue" in people whose occupation renders them incapable of making "any just judgement" about morals or anything else of importance.

Smith's overall estimation of the condition of most poor people also seems much more plausible if one is thinking of the rural poor rather than urban paupers. It seems possible that a country laborer living in a community with poor but virtuous neighbors and stimulated by a diverse range of tasks could lead a reasonably happy life despite his or her poverty. An urban worker, toiling away at a repetitive job that renders him or her as "ignorant as it is possible for a human creature to become," seems much less likely to live happily.

The idea that the poor can take care of themselves in bad times also makes sense only if one is thinking primarily of rural areas. Unlike their urban brethren, agricultural workers have access to food even when it is relatively scarce. Furthermore, rural paupers are much more likely to live in closely-knit communities with neighbors who, because of their station in life, will have developed a degree of virtue that renders them willing to help in bad economic times. Many urban workers will have few ties to

${ }^{37}$ TMS 1.iii.3.5 (pg. 63). 
most of their neighbors, and will therefore not be in much of a position to request or receive help from them. Remember that for Smith, duties of beneficence extend mostly to friends and family. Note also that the tendency of capitalism is to draw more and more people out of rural settings and into urban ones. Although work in the modern retail and service sectors is less mentally and physically stunting than the occupations available to the lower classes in Smith's time, the lack of stimulation available in such jobs is arguably still present in large part.

None of this is meant to imply that Smith was some sort of monster who hated the poor. Smith goes into some detail describing how government action, in the form of the poor laws of England, can work to deny opportunities for betterment to the poor. ${ }^{38}$ He also opposed the idea that low wages for the poor are better for the morals of society than more generous wages. ${ }^{39}$ Surely, Smith genuinely believed that the poor would be better off under his system than others prevalent at the time. Still, his good intentions do not necessarily fully realize themselves in his system.

Smith's discussion of the duties of beneficence is vulnerable to objections similar to those that can be raised about his account of the poor's condition, namely that in both cases, Smith draws generalizations after considering an insufficiently large group of people. Fundamental to Smith's claim that duties of beneficence are optional is the idea that "lelvery man is, no doubt, by nature, first and principally recommended to his own care." ${ }^{40}$ Here Smith most likely has healthy, adult males in mind. Neither a small child, an old or infirm person, nor, in his time, a woman (not allowed to work in most occupations, paid next to nothing in most others, and expected to derive support from her husband) would fit this model very well. Although Smith does note that "It)he laws of all civilized nations oblige parents to maintain their children, and children to maintain their parents," the underlying assumption that most people need or deserve little assistance from others warrants re-examination. ${ }^{41}$ If duties of beneficence are stronger than Smith makes out, the ethical justifications for his economic theory (or at least a laissez-faire interpretation of it) are severely weakened. ${ }^{42}$

\footnotetext{
${ }^{38}$ WN I.x.c.45-59 (pp. 152-57).

39 WN I.viii.36-57 (pp. 96-104).

${ }^{40}$ TMS II.ii.2.1 (pg. 82).
}

${ }^{41}$ TMS II.ii.1.8 (pg. 81).

42 In WN V.i.f.54 (pg. 785), Smith does advocate a kind of minimal public education which would provide instruction in how to "read, write, and account." What other types of government aid to the poor he would approve of is an interesting and difficult question. 
V. Conclusion

Capitalist economic theory has, of course, developed a great deal since Smith wrote. Still, his fundamental ethical justifications are largely intact. Although in consumer economies material goods are probably
regarded as more valuable in and of themselves than in Smith's theory, the underlying reasons for pursuing wealth have remained virtually unchanged. Many now pay lip service to the idea that the rich and the government have some obligation to the poor, but the atomistic view that society is made up of independent individuals solely responsible for their own well-being, which forms the basis for privileging duties of justice over duties of beneficence, is still widely held. The philosophical anthropology and the ethical claims necessary to provide justification for Smith's economic theory, therefore, are still with us today. Especially today, when many countries are converting to capitalist economies or contemplating such a converstion, an examination and critique of these claims and their: consequences is vital. 